\title{
Focusing on the Needs of Engineers in Their Co-op Experiences
}

\author{
Craig James Gunn \\ Department of Mechanical Engineering \\ Michigan State University \\ East Lansing, Michigan
}

\begin{abstract}
Co-operative education is becoming more and more common among the engineers enrolled in university programs today. Students are regularly combining their courses with work in the real world. With this real world experience, students have discovered that they can no longer simply learn technical expertise without the added knowledge of global issues, cultural constraints, and the need for communication skill. It has therefore become vitally important for programs connected with engineering to provide the necessary tools for their students to excel in the world outside the university. In regard to one of the areas of concern, engineering students involved in cooperative education activities at Michigan State University have been given an increasingly larger focus on communication skill needs in the work place. This focus along with the added emphasis on communication excellence in the classroom has provided another vital link between the academic and industrial worlds. The emphasis on communication skill and the methods used to focus awareness on these necessities are addressed in the paper. A seminar procedure is outlined, along with details of the materials provided for student helps in real world situations.
\end{abstract}

Introduction. When students begin their cooperative working assignments, there are many things that are flowing through their minds. They consider the money that they will be earning as part of the work force. They are also entering, in most cases, an environment that is unfamiliar to them. They have not previously been in positions that have required them to become the supervisors of older union workers. They have not experienced jobs that have placed ultimate responsibility upon their decision-making skills. Additionally, they must communicate to many different audiences both inside and outside the working environment. Some must acclimate themselves to totally new living conditions and cultural experiences. They must also consider what they assume to be the expectations of the faculty that they will encounter when they return to the university or college setting. This may seem like a myriad of stimuli bombarding the student, but it is these items that make up the cooperative work experience for our students.

In order for a work experience to be valuable for a student, there is a definite need to analyze the preparation for the experience, the experience itself and how the student moves through that experience, and the debriefing that the student receives when he or she returns to campus. A great number of the students who go on their first cooperative experience have not really been away from home that long, and it is necessary to prepare them for what they will encounter. It is also important to gain a perspective of what the student has experienced during the cooperative assignment. Therefore, well before students leave for their work sites, they must be given a clear indication of what they find out about the workplace. Since a work report is a commonly used method to obtain a grade for the semester's or quarter's work. On the other hand, the work report can be a means by which the students can focus on what is really contained in the work experience beyond the paycheck that they receive at the end of each work period. 
Students are hopefully trained as leaders, but they also must be treated as followers and given directions that will cause them to secure answers to questions that revolve around their experience within industry. If students are left to aimlessly wander during their work experience, they will most likely fail to see some of the important elements of working in their chosen professions during their college or university careers. They also may find that the information for which they are asked to share when they return to their respective schools may have been lost or never even thought about during their experience. It is important to lay sufficient groundwork for the students before they move into the industrial settings. They must know clearly what information they should be researching in the jobs that they are taking. This practice alone may help some to collect information in the future.

One way to encourage students to look closely at their cooperative experience is for them to present them with a detailed block of information that they must investigate during the work that they will do for a particular company. Cooperative Education students who are leaving the College of Engineering at Michigan State University for their first work experience are given clear instructions on the material that they will need to gather in four distinct areas: Nature of the Work Setting, Duties and Responsibilities, Relationship to Career Goals and College Study, and Overall Evaluation. These focal points require that the students go beyond the "What I did last summer" report and delve into the operations of the companies for which they work. This concern for detail provides many students with answers that never would have surfaced under normal working conditions. Since this work experience is intended to provide valuable insight into future career paths, the depth to which students can collect information will be vital to learning.

Objective. With all these things in mind, it is vital to create a means by which the student can look at the cooperative work experience and gain from the knowledge encountered in this experience. The information gathered by the student from a variety of sources, the careful preparation of the faculty for the reports that will be produced by the students, and valuable feedback mechanisms put in place to give students the faculty's response will be the catalysts that make this part of a student's education a worthwhile learning experience.

Methods. This paper looks at the kinds of information that can provide students with a basis upon which to judge the value of their experience. It also provides a means by which the student can diffuse problems that may arise with faculty expectations. Also included is a feedback mechanism for faculty, which can provide students with an increased awareness of the work experience. One of the ways that we suggest to students to make the work experience both valuable and informative is to collect work related information on a regular basis before the work experience starts, during introductory sessions as the experience begins, and continuously during the cooperative work experience. Students need to start collecting information as quickly as they can through methods like the design notebook format, the information collection sheet, and the grammatical guide sheet. Anything that will provide both contents and presentation help should be utilized. 
The design notebook is one tool that is valuable forever. It allows the student to explore his or her technical expertise, inventive mind, and inadequacies over a long period of time. If the engineer starts to collect information immediately the report will unfold with a much greater ease. It will also

Table 1. Info-collection - (* indicates continuous collection throughout semester)

1. Info session - What do you need for the report?

$2^{*}$. Plant tour - What do you see?

$3^{*}$. Co-op job orientation.

What are your responsibilities? What are the objectives of your position?

Why does it exist? Does it utilize your tech. background?

4. Who will you report to and how is this to be done?

5. Does the company have a particular style/format for text production.

Is there anything peculiar about producing text for them?

6*. What previously learned material is to be used for your job?

$7 *$. What new learning must take place for you to complete your assignments?

$8^{*}$. Are there areas that you have not needed to study but have investigated out

of an interest borne of the work assignment?

9. What is the organizational structure of the company?

What are the functions, products, or services of your unit/company?

10. Describe management and the workers in the company.

11 . What is the relation of your unit to the rest of the company?

$12^{*}$.What kind of evaluations have you received and what do they mean?

$13 *$.Detailed account of your activities.

$14 *$. What are you learning?

$15^{*}$. Future assignments.

$16^{*}$. What types of work assignments would be beneficial to your career?

$17^{*}$. Are your career goals reinforced/modified during Co-op?

$18 *$. What is your focus on career goals?

show the writer weaknesses in the text.

Providing students with an information sheet ( Table 1) allows the student to focus on the issues that the reader will find important and informative. Information sheets can be adjusted for any group of students or for a variety of situations. Meeting with students before they go on the cooperative work experience in order to ascertain the kinds of questions that the students themselves would like answered will also bring a sense of ownership to the report and to the questions being asked.

Lastly, it must be realized that even though content is the most important element of the text, a report must conform to writing standards and sufficiently address the educational level of the 
reader. Therefore, it is felt that the student should receive some guidance in the standards to follow. This does not require a great deal of information because most students have adequate tools to produce reports. A simple reminder of the elements of good grammar can help immensely. One way of alerting students to the composition needs of a piece of text is to simply provide a means by which they can review what they know and don't know. In this way, elements that need to be addressed can be easily seized upon.

The students are provided with the following list in order for them to quickly assess whether they know what to do in the case of the item or not. If they do not know, then they must seek answers from any source available.

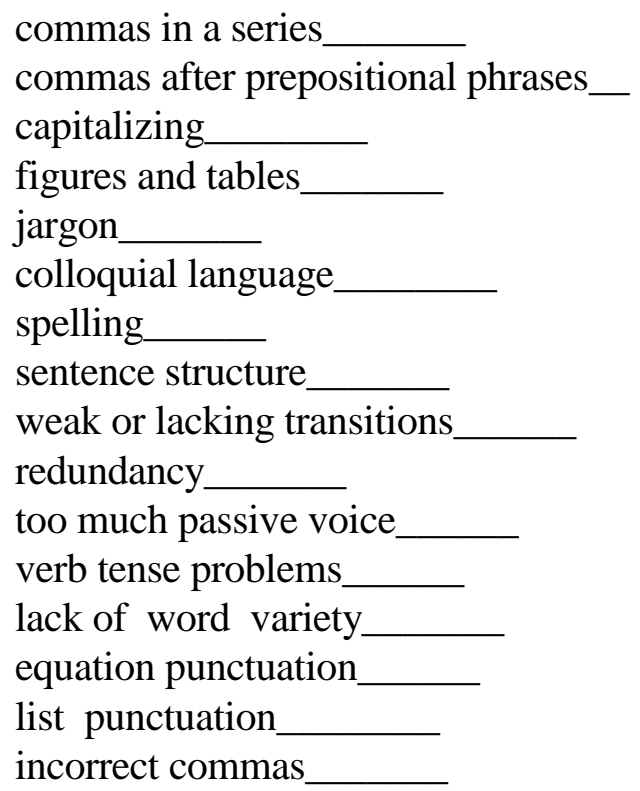

incorrect semi-colons
reference marks [ ]
equation marks ( )
neatness
abbreviations__
,which or that_
This is beginnings__
This is because
awkward wording __
repetition
commas between clauses
section merging
section problems
result lead in
conclusion format_
intro information

All of the above items have been directed to pre-work and collection activities. If these foundations are laid carefully, the work report itself will unfold comfortably for the co-op student.

The following outline gives the student a direction in which to chart the information that is necessary to complete the report.

\section{Nature of the Work Setting}

a. The functions, products, or services of your employing organization.

b. The organizational structure of your employer.

c. The relationship of your unit or department to the overall structure.

d. The objectives of your position. The utilization of your technical background in the position. 


\section{Duties and Responsibilities}

a. A detailed account of your major activities to date (emphasis on the specific technical functions of your position.)

b.Any additional responsibilities you anticipate before the completion of your co-op assignment.

c. Your assignments and their relationship to your field of study.

\section{Relationship to Career Goals and College Study}

a. Ways in which your career goals have been reinforced or modified.

b. Changes in your plans or future coursework

c. Impact of experience on potential career options.

\section{Overall Evaluation}

a. The level to which your employment experience has met your expectations?

b. Ways in which it has differed from your objectives?

c. Ways that your assignment could be improved by your employer?

d. Ways in which it could be improved by you?

e. Level to which your assignment has provided a broad, developmental experience?

f. Level to which your co-op assignment has given you a progressive, in-depth learning experience?

g. Information that your professors should know about your assignment, your educational enrichment, your technical accomplishments and your overall development as an engineer?

For the students then, the answers to the above questions formed into a report can clearly indicate what the work experience has meant to them. Instead of just being comfortable with a good paycheck, students have some very tangible reasons to make intelligent judgements on the value of the experience.

An additional issue that is discussed with the students before they begin work is the level of their technical experience. Many faculty express concern regarding the extent of the technical experience. Since the students coming from the College of Engineering at Michigan State University will ultimately graduate as engineers, it is important that the experiences that they encounter reflect work in the engineering world. The questions that require reflection on the level of engineering performed by the student can bring out a whole spectrum of valuable experiences, but they also may reflect a more elementary experience that may not be acceptable to some members of the faculty. If these faculty members are evaluating the reports, bias may slip into the process. Students carefully relating their experiences, may discover negative responses that defy understanding. If an experience is very mundane, students have difficulty in making it more than it is. Here the coordinators of the program can step in to provide a supplementary avenue that will provide the technical direction for the faculty member and another valuable experience for the student. If students find that little they will encounter little technical responsibility in their work 
experience, they must then take the initiative to research topics that encompass work that is being done at the companies for which they work, even though they themselves may not be connected with that work.

The student must become involved in the work experience as more than just a job but a complete spectrum on what it means to be part of the company and the workforce. It is strongly suggested that the students utilize the materials that are provided to them before they begin work to prepare their own outlines, checklists, collection sheets to make sure that all pertinent information is collected. If students work in situations that do require technical knowledge and application, design notebooks should be started or continued from previous experiences. This notebook will give students a continuous record of work done so that details will not be forgotten during the course of the work experience. This collection technique will also serve to focus the students' attention on more than just the aspect of being paid for working.

After the report is prepared, students are strongly advised to prepare an informational abstract that gives an overview of the completed report. Not only for the students benefit, but also for any reader,so that they will know before hand what will be covered in the report. This is especially helpful when a readers have preconceived notions of what they feel should be contained in the report and read with those notions at the forefront. This informational ABSTRACT can provide readers with a review of the information is contained in the report. It should indicate more than just broad generalizations, i.e. I had a job at TRW. This abstract also allows the writer to explain to the reader the overall scope of the work experience, which may or may not contain a great deal of technical content.

The report, then, as it is submitted reflects a true learning experience for the student. It does not simply become an exercise in presenting information for no real purpose. The process of preparing for the text production is to allow the student to immerse himself or herself in the work experience.

Students going on their first co-op experience are required to participate in a 2 1/2-hour seminar which gives an in-depth look at the work report and issues that relate to communication in the real world. The topics discussed include the work report that will be used as the grade for the co-op semester, audience concerns, language issues, and the ever-present grammatical concerns.

Conclusions. The work report produced by co-op students is a valuable tool, which allows students to investigate their work experience and the means to present that information. Through careful planning, this report can provide vital information for future career pursuits. It also enables faculty members who have not had extensive experience with the working world outside the university to view this world. The benefits of a carefully prepared work report reflect its need in the cooperative experience. The work report, then serves to give students a more concentrated focus on the work experience. It provides an impetus to seek information that will shape their ideas of working in their career areas. It will broaden the scope of work to take in all the elements that are necessary to make a career successful and enjoyable. The techniques of setting up information collection outlines, preparing design notebooks and abstracts will also provide readers with a clear indication of what has occurred during the work experience. Collecting the information is valuable, but presenting it to 
the public is especially important. Making an assignment into a true learning experience requires an enormous effort, but this effort can be very valuable if carefully orchestrated.

CRAIG JAMES GUNN is the Director of the Communication Program in the Department of Mechanical Engineering. Author of numerous papers on communication within engineering, he also spends time with co-op students helping to prepare them for the working environment. With degrees in English, he holds a unique place with which to provide support to engineering students as an in-house guide to communication. 